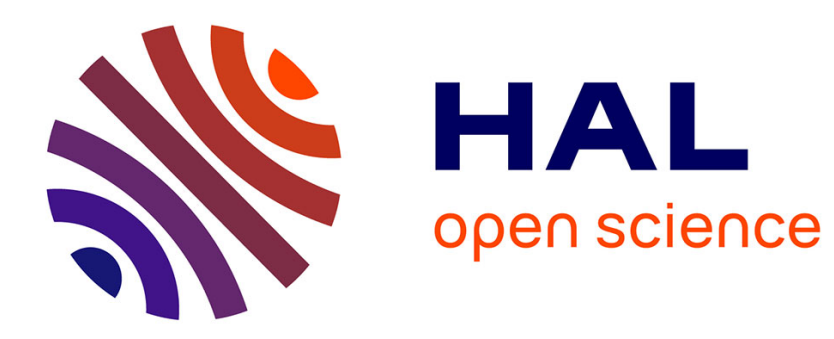

\title{
A positron beam study of defects in $\mathrm{SiO} 2$
}

M. Fujinami, N. Chilton, K. Ishii, Y. Ohki

\section{To cite this version:}

M. Fujinami, N. Chilton, K. Ishii, Y. Ohki. A positron beam study of defects in SiO2. Journal de Physique IV Proceedings, 1993, 03 (C4), pp.C4-169-C4-175. 10.1051/jp4:1993423 . jpa-00251466

\section{HAL Id: jpa-00251466 https://hal.science/jpa-00251466}

Submitted on 1 Jan 1993

HAL is a multi-disciplinary open access archive for the deposit and dissemination of scientific research documents, whether they are published or not. The documents may come from teaching and research institutions in France or abroad, or from public or private research centers.
L'archive ouverte pluridisciplinaire HAL, est destinée au dépôt et à la diffusion de documents scientifiques de niveau recherche, publiés ou non, émanant des établissements d'enseignement et de recherche français ou étrangers, des laboratoires publics ou privés. 


\title{
A positron beam study of defects in $\mathrm{SiO}_{2}$
}

\author{
M. FUJINAMI, N.B. CHILTON, K. ISHII ${ }^{*}$ and Y. OHKI ${ }^{*}$
}

Advanced Materials \& Technology Research Laboratories, Nippon Steel Corporation Ida, Nakahara-ku, Kawasaki, Japan

" Department of Electrical Engineering, Waseda University, Shinjuku-ku, Tokyo, Japan

\begin{abstract}
Defects in crystalline and amorphous $\mathrm{SiO}_{2}$ were studied by variable-energy positron annihilation spectroscopy in an attempt to clarify what defects in $\mathrm{SiO}_{2}$ are observable in positron annihilation studies. The level of the $S$ parameter in amorphous $\mathrm{SiO}_{2}$ films grown by plasma chemical vapor deposition (CVD) in a tetraethylorthosilicate (TEOS) and $\mathrm{O}_{2}$ atmosphere was found to be correlated to the concentration of $\mathrm{Si}-\mathrm{OH}$ in the silicon dioxide layer. The difference in $\mathrm{S}$ parameter between crystalline and amorphous $\mathrm{SiO}_{2}$ is assumed to be due to the effects of para-Ps self-annihilation in free volumes in the amorphous sample. The $\mathrm{S}$ parameters in crystalline and thermally grown silicon dioxide were both found to decrease after $C$ ion implantation $\left(1 \times 10^{14} \mathrm{~cm}^{-2}, 140 \mathrm{keV}\right)$ or alternatively, ArF excimer laser $(6.4 \mathrm{eV})$ irradiation. Both methods are expected to produce numerous types of Frenkel defects of which, it is most likely that negatively charged species such as $\equiv \mathrm{Si}^{-} \mathrm{O}^{-}$are the trapping sites. In the case of ion implantation into amorphous $\mathrm{SiO}_{2}$ a greatly lowered $\mathrm{S}$ parameter is observed, this is explained as a combination of defect trapping and reduction in para Ps production after ion implantation.
\end{abstract}

\section{Introduction}

The analysis of near-surface defects by use of variable-energy positron beams has, in the last decade, become practical(1). As research efforts are afforded to understanding the behavior of the positron when it interacts with various defects, this technique is able increasingly to provide unique information about the defects themselves and the processes by which defects are created or recovered. In particular, the behavior of defects (vacancies) in ion implanted silicon is gradually becoming understood (2-4). However, in order to interpret precisely the positron data from real silicon-based semiconductors, it is very important to understand the behavior of positrons in $\mathrm{SiO}_{2}$ and at the $\mathrm{SiO}_{2} / \mathrm{Si}$ interface because such device quality wafers usually incorporate an oxide film of some thickness which can strongly influence the positron data $(5,6)$. For example, annihilation in the thin native oxide layer of a Si wafer gives rise to a lower $\mathrm{S}$ parameter than for annihilation in bulk amorphous $\mathrm{SiO}_{2}$. We always observe the $\mathrm{S}$ parameter for annihilation at the $\mathrm{SiO}_{2} / \mathrm{Si}$ interface to be slightly lower than that of bulk $\mathrm{Si}$ or $\mathrm{SiO}_{2}(7)$. Further, it has been found that ion implantation into amorphous $\mathrm{SiO}_{2}$ results in a very low $S$ parameter $(8,9)$. The origins of these phenomena are still unresolved.

We have studied crystalline and vitreous bulk $\mathrm{SiO}_{2}$, and thermally oxidized and plasma CVD grown $\mathrm{SiO}_{2}$ films on $\mathrm{Si}$. The former three samples have been irradiated with an $\mathrm{ArF}$ excimer laser $(6.4 \mathrm{eV})$ or $\mathrm{C}$ ion implanted $\left(1 \times 10^{14} \mathrm{~cm}^{-2}, 140 \mathrm{keV}\right)$ in order to induce positron trapping centers in the samples. The many types of defects generally present in irradiated/implanted $\mathrm{SiO}_{2}$ samples are summarized in Table 1. The aim of this article is to recognize which of these defects in $\mathrm{SiO}_{2}$ are observable in positron annihilation studies. 
Table 1 Defects in silicon dioxide. The - mark indicates an unpaired electron (radical) and the $\equiv$ mark indicates silicon bonding with 3 oxygen atoms.

\begin{tabular}{lcc}
\hline \hline name of defect & schematic & charge transfer state \\
\hline E' center & $\equiv \mathrm{Si} \bullet$ & $\equiv \mathrm{Si}^{+}$ \\
nonbridging-oxygen hole & $\equiv \mathrm{Si}-\mathrm{O} \bullet$ & $\equiv \mathrm{Si}^{-} \mathrm{O}^{-}$ \\
center (NBOHC) & $\equiv \mathrm{Si}-\mathrm{O}-\mathrm{O} \bullet$ & $\equiv \mathrm{Si}-\mathrm{O}_{-}-\mathrm{O}^{-}$ \\
peroxy radical (PR) & $\equiv \mathrm{Si}-\mathrm{Si} \equiv$ & \\
oxygen vacancy & $\equiv \mathrm{Si}-\mathrm{O}-\mathrm{O}-\mathrm{Si}$ & \\
peroxy linkage (PL) & $\mathrm{O} 2$ & $\mathrm{O}_{2}^{-}$ \\
dissolved oxygen & $\equiv \mathrm{Si}-\mathrm{OH}$ & \\
impurity & $\equiv \mathrm{Si}-\mathrm{H}$ & \\
impurity &
\end{tabular}

\section{Experimental}

The crystalline and vitreous $\mathrm{SiO}_{2}$ bulk samples were of commercially available type. The wet oxidation $\mathrm{SiO}_{2}$ film (abbreviated in the following as wet $\mathrm{SiO}_{2} / \mathrm{Si}$ ) had $500 \mathrm{~nm}$ thickness and was grown on a Czochralski $(\mathrm{Cz}) \mathrm{Si}(100)$ wafer $\left(10 \Omega \mathrm{cm}\right.$, p-type) in $\mathrm{O}_{2}$ and $\mathrm{H}_{2}$ at $1100^{\circ} \mathrm{C}$ for 55 minutes. The plasma CVD oxide films (abbreviated in the following as plasma $\mathrm{CVD} \mathrm{SiO}_{2} / \mathrm{Si}$ ) were deposited on a $\mathrm{Cz}-\mathrm{Si}(100)$ wafer $\left(1-3 \Omega \mathrm{cm}, \mathrm{p}\right.$-type) using tetraethylorthosilicate (10) (TEOS, $\left.\mathrm{Si}\left(\mathrm{OC}_{2} \mathrm{H}_{5}\right)_{4}\right)$. During plasma CVD growth, oxygen and TEOS gases flowed into the deposition chamber at a rate of $10 \mathrm{sccm}$ and $1 \mathrm{sccm}$, respectively. During deposition, RF power of $20 \mathrm{~W}$ was applied and the pressure was 0.2 Torr. Six samples with Si substrate temperatures ranging from $100^{\circ} \mathrm{C}$ to $600^{\circ} \mathrm{C}$ were grown by the plasma CVD technique. The thickness of these $\mathrm{SiO}_{2}$ films was measured to be $300 \mathrm{~nm}$ for the films deposited at $100^{\circ} \mathrm{C}$ and $600^{\circ} \mathrm{C}$, and $500 \mathrm{~nm}$ for the others. For each of these $\mathrm{SiO}_{2}$ films, an etching rate determination was made using a solution of 0.25 vol\% $\mathrm{HF}$. The films mentioned above are, of course, amorphous.

Crystalline and wet $\mathrm{SiO}_{2}$ samples were either irradiated by an $\mathrm{ArF}$ excimer laser $(6.4 \mathrm{eV})$ or implanted with $C$ ions. For the laser irradiation, an area of $150 \mathrm{~mm}^{2}$ was exposed to the unfocused beam from an excimer laser (Lambda Physik $210 \mathrm{i}^{\prime \prime} \mathrm{F}^{\prime \prime}$ ) at $50 \mathrm{~Hz}$ for 15 minutes, the exposed area is much larger than that of the positron beam used for analysis. The average power density was estimated to be $30 \mathrm{~mJ} / \mathrm{cm}^{2}$ per pulse. For C ion implantation, the energy and dose were $140 \mathrm{keV}$ and $1 \times 10^{14} \mathrm{~cm}^{-2}$, respectively. The mean projected range and standard deviation of the $\mathrm{C}$ ions in the samples were $297 \mathrm{~nm}$ and $58 \mathrm{~nm}$, respectively.

The Nippon Steel Corporation variable-energy positron beam was used to measure the $S$ parameter data with respect to incident positron energies in the range 0 to $30 \mathrm{keV}$ at room temperature(11). The experimental pressure was maintained at $10^{-9}$ Torr. Infrared absorption spectra were measured for plasma CVD $\mathrm{SiO}_{2}$ using a JIR-100 FT-IR spectrometer (JEOL) at room temperature. Quantitative analysis of the $\mathrm{Si}-\mathrm{OH}$ and $\mathrm{H}-\mathrm{OH}$ content in these $\mathrm{SiO}_{2}$ films was made by Pliskin's method using the absorption lines: $\mathrm{Si}-\mathrm{OH}\left(3650 \mathrm{~cm}^{-1}\right)$ and $\mathrm{H}-\mathrm{OH}\left(3330 \mathrm{~cm}^{-1}\right)(12)$. We define and use $\mathrm{H}-\mathrm{OH}$ here as meaning hydrogen bonded $\mathrm{OH}$.

\section{Results and discussion}

Fig. 1 shows the $S$ parameters vs. positron energy curves (hereafter referred to as $S$-E curves) for the crystalline and vitreous $\mathrm{SiO}_{2}$ bulk samples, and the wet $\mathrm{SiO}_{2} / \mathrm{Si}$ sample. The $\mathrm{S}$ parameter of the vitreous and the thermally oxidized $\mathrm{SiO}_{2}$ was almost identical to that of bulk $\mathrm{Si}$. The fortuitous identical $\mathrm{S}$ parameters for $\mathrm{Si}$ and amorphous $\mathrm{SiO}_{2}$ makes it very easy to see a lowering of the $\mathrm{S}$ parameter at around $8 \mathrm{keV}$ due to the $\mathrm{SiO}_{2} / \mathrm{Si}$ interface. Further, the S-E curves of crystalline $\mathrm{SiO}_{2}$ have a gentle change in the low positron energy region, indicating that the diffusion length of the positron in crystalline $\mathrm{SiO}_{2}$ is much longer than that in amorphous $\mathrm{SiO}_{2}$. 


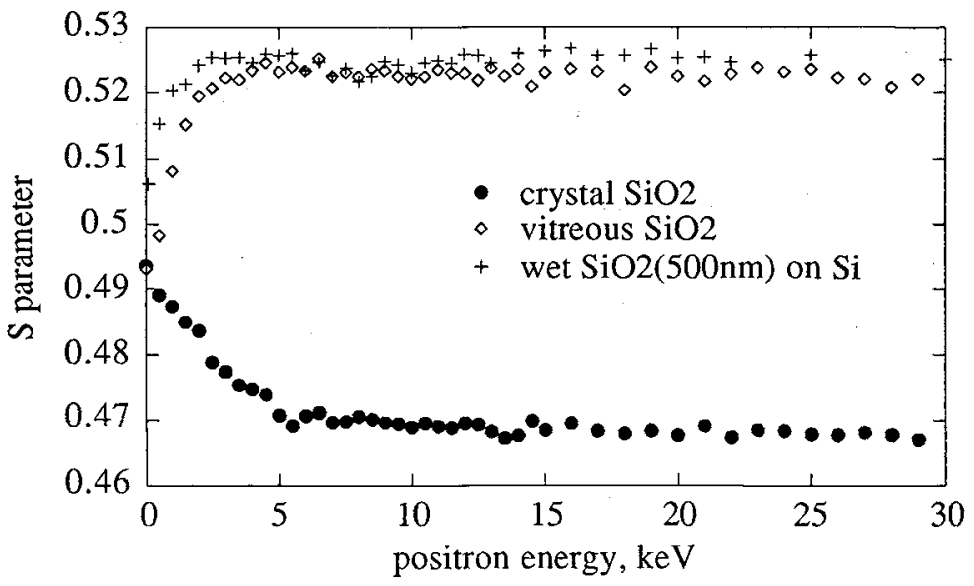

Fig. 1 The $\mathrm{S}$ parameter-positron energy curves for crystalline $(\bullet)$ and vitreous $(\diamond) \mathrm{SiO}_{2}$, and the wet thermally grown $\mathrm{SiO}_{2}$ film( $(+)$ of $500 \mathrm{~nm}$ thickness on $\mathrm{Si}(100)$.

The $\mathrm{S}$ parameter for bulk crystalline $\mathrm{SiO}_{2}$ is greatly different to that of amorphous $\mathrm{SiO}_{2}$. Due to the greater free volume in amorphous $\mathrm{SiO}_{2}$, the formation probability of positronium (Ps), is much higher than that in the crystal and usually goes up to several tens of $\%(13,14)$. Such Ps formation results in an increase in the $S$ parameter due to its subsequent self-annihilation with consequently low Doppler broadening. The density of amorphous $\mathrm{SiO}_{2}$ is lower than that of the crystal and this is also indicative of the greater free volume in the amorphous material. It can be concluded that a difference in Ps formation is primarily responsible for the difference in $S$ parameters between amorphous and crystalline $\mathrm{SiO}_{2}$.

Fig. 2 shows the S-E curves of the plasma CVD $\mathrm{SiO}_{2}$ films. It was found that the $\mathrm{S}$ parameter level in the $\mathrm{SiO}_{2}$ was strongly dependent on the deposition substrate temperature. The curvature in the data in the near surface region is either due to positron diffusion in the oxide layer (unlikely as it is amorphous), or that there is a gradient concentration of out-diffusing impurities in the near surface region. Whatever the reason, it does not affect the conclusion that the level of the $S$ parameter at an energy where the positrons all annihilate in the oxide layer $(\approx 3 \mathrm{keV})$ varies in correspondence with the substrate temperature. At $600^{\circ} \mathrm{C}$ the curve is almost identical to that of the thermally grown $\mathrm{SiO}_{2}$ specimens.

The etching rates (which are an index to the density of the $\mathrm{SiO}_{2}$ films) for the plasma CVD $\mathrm{SiO}_{2}$ samples are shown in Table 2 . As the substrate temperature increased, the etching rate decreased thus indicating that the $\mathrm{SiO}_{2}$ deposited at higher temperature was denser, or has smaller free volume. Therefore, the difference in $\mathrm{S}$ parameters for the plasma CVD $\mathrm{SiO}_{2}$ films was not caused by a differing para-Ps self annihilation rate as this would cause an opposite trend to that observed. We thus have to consider other types of defects which may suppress Ps formation or otherwise affect the Ps annihilation, pick-off or spin conversion processes. 


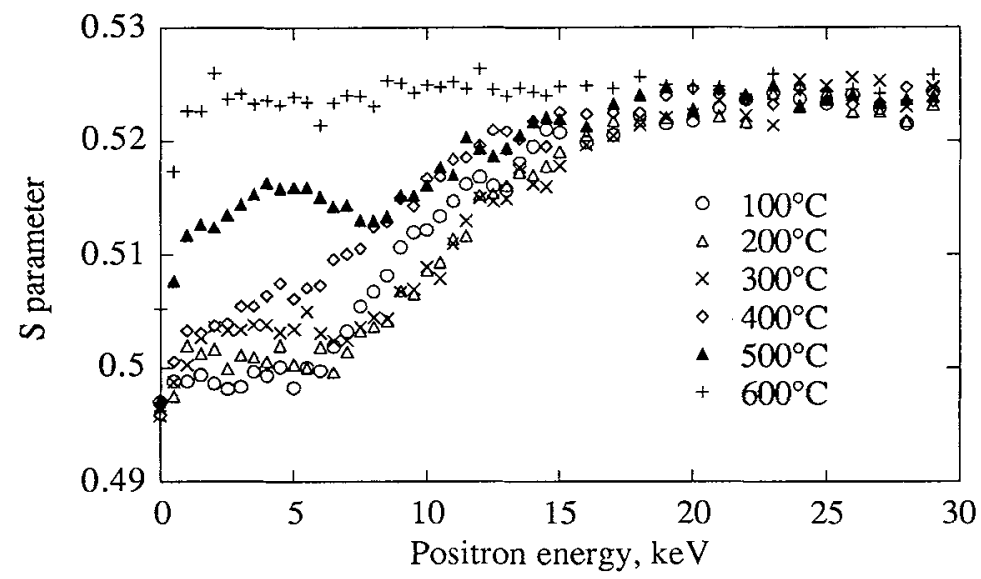

Fig. 2 The S parameter-positron energy curves for the plasma CVD $\mathrm{SiO}_{2}$ films deposited on $\mathrm{Si}(100)$ in a tetraethylorthosilicate and oxygen atmosphere at the indicated substrate temperatures.

Table 2 lists the concentrations of Si-OH and $\mathrm{H}-\mathrm{OH}$ derived from our IR data. It should be noted that the $\mathrm{Si}-\mathrm{H}$ absorption band (around $2100 \mathrm{~cm}^{-1}$ ) was absent and that a very sharp absorption peak at $1070 \mathrm{~cm}^{-1}$ due to Si-O-Si appeared in all of the IR spectra. It was found that there was a rather high concentration of $\mathrm{Si}-\mathrm{OH}$ and $\mathrm{H}-\mathrm{OH}$ involved in the plasma CVD SiO 2 films, whereas this means of analysis indicated that none of the thermally oxidized $\mathrm{SiO}_{2}$ films contained detectable $\mathrm{Si}-\mathrm{OH}$ or $\mathrm{H}-\mathrm{OH}$. The crystalline $\mathrm{SiO}_{2}$ sample is stated to have an $\mathrm{OH}$ concentration of less than $2 \mathrm{ppm}$. The content of $\mathrm{H}_{2} \mathrm{O}$ monotonically decreased as the substrate temperature increased, whereas that of Si$\mathrm{OH}$ was almost constant in the range $100^{\circ} \mathrm{C}$ to $400^{\circ} \mathrm{C}$ and greatly decreased at $500^{\circ} \mathrm{C}$ and $600^{\circ} \mathrm{C}$. Thus, the level of the S parameter in the oxide film, shows a correlation to the Si-OH concentration at those temperatures. It is, therefore, proposed that the $\mathrm{S}$ parameter in amorphous $\mathrm{SiO}_{2}$ is strongly influenced by the $\mathrm{Si}-\mathrm{OH}$ concentration present and that positrons or Ps tend to be trapped in the region of the Si-OH species. The porosity of the $\mathrm{SiO}_{2}$ films increased as the $\mathrm{Si}-\mathrm{OH}$ concentration increased thus indicating that the surroundings of the $\mathrm{Si}-\mathrm{OH}$ species has more open space than that of normally bonded $\equiv \mathrm{Si}-\mathrm{O}-\mathrm{Si} \equiv$. As the presence of $\mathrm{Si}-\mathrm{OH}$ (silanol) resulted in a lowering of the $\mathrm{S}$ parameter, we propose that the silanols are related to a Ps reaction, which suppresses the formation of para-Ps or its self annihilation.

Table 2. Influence of substrate temperatures for the plasma CVD $\mathrm{SiO}_{2}$ films on etch rate, and the $\mathrm{H}-\mathrm{OH}$ and $\mathrm{Si}-\mathrm{OH}$ concentrations deduced from IR measurement. The data of wet $\mathrm{SiO}_{2}$ films are shown for comparison.

\begin{tabular}{cccc}
\hline \hline $\begin{array}{c}\text { Substrate temperature } \\
\left({ }^{\circ} \mathrm{C}\right)\end{array}$ & $\begin{array}{c}\text { Etch rate } \\
(\mathrm{nm} / \mathrm{min})\end{array}$ & $\begin{array}{c}\mathrm{H}-\mathrm{OH} \text { concentration } \\
(\text { wt\% })\end{array}$ & $\begin{array}{c}\text { Si-OH concentration } \\
(\text { wt } \%)\end{array}$ \\
\hline 100 & 25 & 4.1 & 2.2 \\
200 & 21 & 3.4 & 3.4 \\
300 & 16 & 2.4 & 4.5 \\
400 & 13 & 1.5 & 4.0 \\
500 & 9.6 & not detectable & 2.0 \\
600 & 5.3 & not detectable & 0.3 \\
wet $\mathrm{SiO} 2$ & 1.5 & not detectable & not detectable \\
\hline \hline
\end{tabular}


Figure 3 shows the data for the crystalline and wet $\mathrm{SiO}_{2} / \mathrm{Si}$ samples before and after irradiation with the ArF excimer laser $(6.4 \mathrm{eV})$. Laser radiation is known to cause the formation of some of the Frenkel-type defects, shown in Table $1(15,16)$. The primary defects created are the E' center, $\mathrm{NBOHC}$ and their charge transfer states. As the laser is unable to structurally alter $\mathrm{SiO}_{2}$, these samples are unaffected by free volume change, so that we can assume that Ps formation probability is unchanged by the laser irradiation. The high transmittance of the laser radiation in the $\mathrm{SiO}_{2}$ can be seen in the effect it has on the crystalline sample. The irradiation causes uniform defect formation to a depth far below the maximum depth probed by the positrons, hence the $S$-E curves are parallel up to $30 \mathrm{keV}$ and the $S$ parameters decreased slightly and uniformly. Radicals species such as the $E^{\prime}$ center and NBOHC are likely to promote pick-off annihilation which would result in an increase of S parameter. Therefore, we conclude that it is the charge transfer species that react with positrons or Ps, and thus lead to a lowering of $S$ parameter.

For the wet $\mathrm{SiO}_{2} / \mathrm{Si}$ sample the effect of the laser is again to uniformly lower the S-E curve in the energy region corresponding to positron annihilation in the $\mathrm{SiO}_{2}$ layer $(0-8 \mathrm{keV})$. Further, the laser irradiation lowers the S-E curve in the Si substrate region more strongly. The origin of the lower $\mathrm{S}$ parameter in the $\mathrm{SiO}_{2}$ region is the same as that for the crystalline sample. On the other hand, the low $\mathrm{S}$ parameters in the $\mathrm{Si}$ region cannot be explained by the same reasoning. It was found that the level of lowering was largest at the $\mathrm{SiO}_{2} / \mathrm{Si}$ interface. We can explain this behavior if a charge transfer species accumulates at the $\mathrm{SiO}_{2} / \mathrm{Si}$ interface and thus leads to an electric field which strongly influences the positron diffusion behavior.

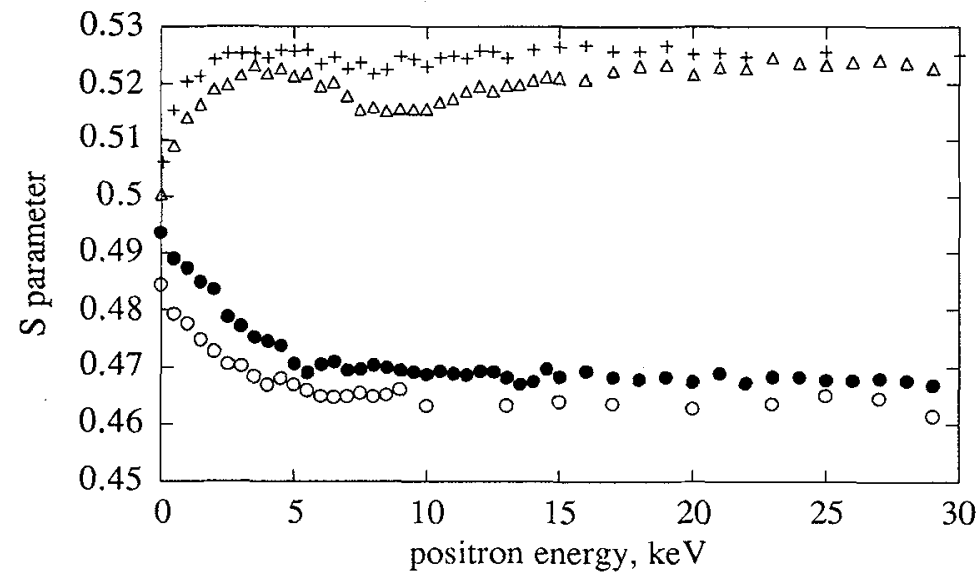

Fig. 3 The $\mathrm{S}$ parameter-positron energy curves for crystalline $\mathrm{SiO}_{2}(\bullet$ :as-received, o:after laser irradiation) and the $500 \mathrm{~nm}$ wet thermally grown $\mathrm{SiO}_{2}$ on $\mathrm{Si}$ films ( + :as-grown, $\Delta$ :after laser irradiation). Laser radiation $6.4 \mathrm{eV}$.

Figure 4 shows the effect of carbon ion implantation on the S-E curves for the crystalline and wet $\mathrm{SiO}_{2} / \mathrm{Si}$ samples. For both samples, the effect of ion implantation is to lower the $\mathrm{S}$ parameter in the region in which $\mathrm{C}$ ions are implanted. The positron trapping is saturated for the amorphous sample shown here as higher dose implantation was not found to further change the S-E curve. It is important to note that the $\mathrm{S}$ parameter is lowered by ion implantation in crystalline $\mathrm{SiO}_{2}$ whereas it is raised by similar ion implantation into crystalline Si. The formation of vacancy type defects in $\mathrm{Si}$ is accepted to be responsible for a raised $\mathrm{S}$ parameter but in $\mathrm{SiO}_{2}$ the positron trapping is dominated by the types of defects listed above for the laser irradiated case. Ion implantation into the crystalline sample may cause some free volume increase by vacancy formation, yet the S parameter is lowered, hence it may be that there are two competing effects here. The two competing effects are positron trapping at Frenkel type defects, which gives rise to a low S parameter, and, positron trapping at open volume defects, which give rise to a high $S$ parameter. It is concluded that the former is predominant in this 
system. For implantation doses high enough to amorphize the crystalline sample it is expected that the $S$ parameter would increase.

For the case of the wet $\mathrm{SiO}_{2} / \mathrm{Si}$ sample the $\mathrm{S}$ parameter after implantation is seen to drop to an extremely low level and the positron or positronium is strongly trapped. This drop is attributable to the Frenkel defects and their charge transfer states listed above. In particular our previous study utilizing electron spin resonance (ESR) and annealing behavior analysis revealed that the positron is most likely to be trapped at the negatively charged states such as $\mathrm{NBOHC}^{-}$or $\mathrm{O}_{2}^{-}(8)$. The drop seen in $S$ parameter is larger than that observed for the crystalline case, this may be because of competing $S$ parameter effects in the crystalline case or, it may be due to a decrease in free volume caused by ion implantation. The latter assertion is not based on experimental results or observations.

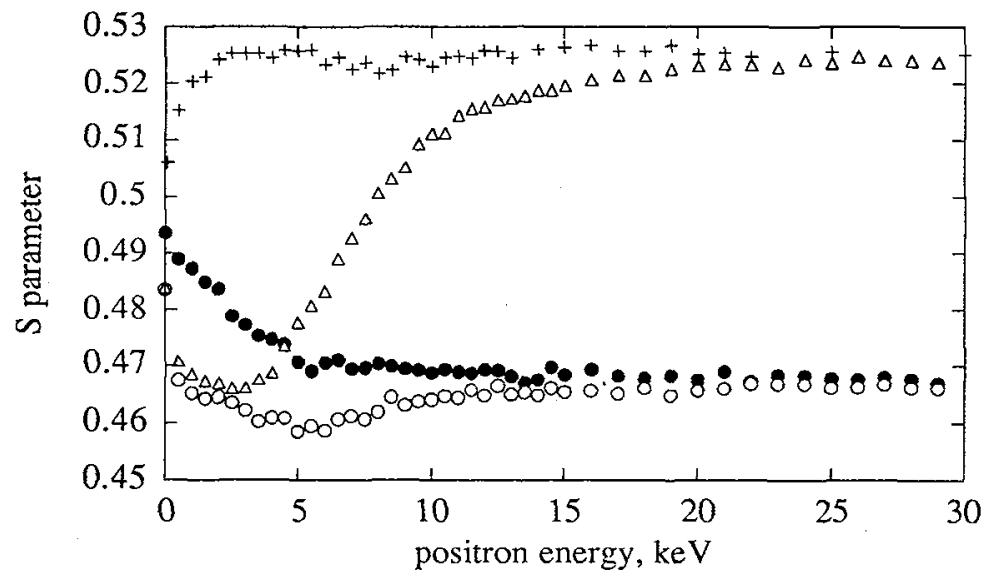

Fig. 4 The $\mathrm{S}$ parameter-positron energy curves for crystalline $\mathrm{SiO}_{2}$ ( $\bullet$ :as-received, o:after ion implantation) and the wet thermally grown $\mathrm{SiO}_{2}$ films of $500 \mathrm{~nm}$ thickness on $\mathrm{Si}(100)$ (+:as-grown, $\Delta$ :after ion implantation). C ion implantation $\left(140 \mathrm{keV}, 1 \times 10^{14} \mathrm{~cm}^{-2}\right.$ ).

\section{Conclusion}

The origins of change in the $\mathrm{S}$ parameter in $\mathrm{SiO}_{2}$ were discussed. The $\mathrm{S}$ parameter difference between amorphous and crystalline $\mathrm{SiO}_{2}$ is almost certainly caused by differences in Ps formation probability due to differing internal free volumes. It is, further, postulated that the $\mathrm{Si}-\mathrm{OH}$ content in plasma CVD $\mathrm{SiO}_{2} / \mathrm{Si}$ is responsible for the different $\mathrm{S}$ parameter levels observed in those samples. We conclude that the silanol species are participating in a reaction that causes the suppression of para Ps formation or its self-annihilation. Laser irradiation is seen to produce defects of a similar type to those caused by $\mathrm{C}$ ion implantation but causes none of the structural modification that clouds the interpretation of the ion implanted data. The structural changes in the ion implanted samples give rise to two effects: the lowering of $S$ parameter for annihilation in the Frenkel defects, and the increasing (lowering) of $S$ parameter as internal free volume increases (decreases). These effects may combine to produce the very low value of $S$ parameter seen in the ion implanted amorphous sample but compete in the ion implanted crystalline case.

There are thus many factors which affect the positron data for $\mathrm{SiO}_{2}$ and until these factors are fully understood we cannot analyze unambiguously positron data for true industrial semiconductor samples. Further systematic research, particularly in the field of positron lifetime studies and reliable preparation of $\mathrm{SiO}_{2}$ samples is necessary in order to be able to classify the defects present and understand which are observable in positron annihilation spectroscopy.

Acknowledgments

This work was financed in part by a NEDO grant for International Joint Research. 


\section{References}

/1/ SCHULTZ, P.J., and LYNN, K.J., Rev. Mod. Phys. 60 (1988) 701

12/ FUJINAMI, M., and CHILTON, N.B., J. Appl. Phys. 73 (1993) 3242

13/ SIMPSON, P.J., VOS, M., MITCHELL, I.V., WU, C., and SCHULTZ, P.J., Phys. Rev. B 44 (1991) 12180

14/ UEDONO, A., WEI, L., DOSHO, C., H. KONDO, TANIGAWA, S., SUGIURA, J., and OGASAWARA, M., Jpn. J. Appl. Phys. 30 (1991) 201

15/ LEUNG, T.C., ASOKA-KUMAR, P., NIELSEN, B., and LYNN, K.G., J. Appl. Phys. 73, (1993) 168

16/ WEI, L., TABUKI, Y., KONDO, H., TANIGAWA, S., NAGAI, R., AND TAKEDA, E., J.

Appl. Phys. 70 (1991) 7543

77/ NIELSEN, B., LYNN, K.G., CHEN Y.-C., and WELCH, D.O., Appl. Phys. Lett. 51 (1987) 1022

18/ FUJINAMI, M., and CHILTON, N.B., Appl. Phys. Lett. 62 (1993) 1131

19/ NIELSEN., B., LYNN., K.G., LEUNG, T.C., CORDTS, B.F., and SERAPHIN, S., Phys. Rev. B 44 (1991) 1812

/10/ NGUYEN, S., DOBUZINSKY, D., HARMON, D., GLEASON, R., and FRIDMANN, S., J.

Electrochem. Soc. 137 (1990) 2209

/11/ FUJINAMI, M., Hoshasen 18(2) (1992) 55

/12/ PLISKIN, W.A., J. Vac. Sci. Technol. 14 (1977) 1064

/13/ COUSSOT, G., and PAULIN, R., J. Appl. Phys. 43 (1972) 1325

/14/ MBUNGU-TSUMBU, SEGERS, D., DORIKENS, M., DORIKENS-VANPRAET, L., C.

LAERMANS, C., and VAN DEN BOSCH, A., J. Non-Cryst. Solids 65 (1984) 131

/15/ NISHIKAWA., H., NAKAMURA, R., TOHMON, R., OHKI, Y., SAKKURAI, Y.,

NAGASAWA, K., and HAMA, Y., Phys. Rev. B 41 (1990) 7828
/16/ GRISCOM, D.L., and FRIEBELE, E.J., Radiat. Effects 65 (1982) 63 